\title{
A FUNÇÃO SOCIAL DA BIBLIOTECA: CONTRIBUIÇÕES PARA A FORMAÇÃO DE LEITORES
}

\author{
LIBRARY'S SOCIAL FUNCTION: \\ CONTRIBUTIONS TO READERS' FORMATION
}

\author{
Dijan Leal de Sousa ${ }^{1}$ \\ Maria José de Pinho
}

\begin{abstract}
Resumo: Este artigo aborda a importância da formação de leitores com ênfase na função social da biblioteca e do bibliotecário como mediadores desse processo. Iniciamos o trabalho com uma breve abordagem, a partir de KLEIMAN (1995; 2011) e FREIRE (1987) sobre o processo de alfabetização, momento necessário e crucial para a formação de leitores assim como as contribuições da habilidade de leitura e escrita para a vida dos indivíduos. Com o objetivo de compreender a função social da biblioteca, bem como a responsabilidade do bibliotecário como intelectual essencial para fomentar o acesso de livros aos leitores, foi realizada uma breve revisão de literatura tendo como principais referências CASTRILLÓN (2011), LAJOLO \& ZILBERMAN (1996). O trabalho apresenta ainda, uma breve análise a partir de uma entrevista com uma bibliotecária, a partir de um projeto desenvolvido que teve como objetivo oportunizar o acesso de livros para usuários do transporte coletivo de Imperatriz/MA, Projeto Parada Literária. A partir da análise, foi possível constatar que a entrevistada tem consciência da função do bibliotecário na realização de ações que aproximem o leitor do espaço da biblioteca e dos livros, embora muito ainda precise ser feito para concretizar estas ações e torná-las cada vez mais presentes em nossa realidade.
\end{abstract}

Palavras chave: formação de leitores; bibliotecário; Projeto Parada Literária.

\begin{abstract}
This article approaches the importance of readers development with an emphasis on the social function of the library and librarian as mediators of this process. We began this work with a brief approach from KLEIMAN (1995; 2011) and FREIRE (1987) on the literacy process, a necessary and crucial moment for the formation of readers as well as the contributions of reading and writing skills to the life of the individuals. In order to understand the social function of the library, as well as the librarian's responsibility as an essential intellectual to foster book access to readers, a brief literature review was conducted with the main references CASTRILLÓN (2011), LAJOLO \& ZILBERMAN (1996).). The paper also presents a brief analysis from an interview with a librarian, from a project that was developed aiming to provide access to books for users of public transport in Imperatriz/MA, the Parada Literária Project. From the analysis, it was found that the interviewee is aware of the role of the librarian in performing actions that bring the reader closer to the space of the library and books, although
\end{abstract}

\footnotetext{
${ }^{1}$ Professora da Universidade Federal do Maranhão (UFMA). Mestre em Educação pela UFMA. Doutoranda do Programa de Pós-graduação em Letras: Ensino de Língua e Literatura da Universidade Federal do Tocantins (PPGL/UFT)- Campus de Araguaína/TO. E-mail: dijan.leal@ufma.br

2 Professora Associada II - Universidade Federal do Tocantins (UFT) Campus de Palmas. E-mail: mjpgon@mail.uft.br
} 
much still needs to be done to make these actions and make them increasingly present in our reality.

Keywords: readers development; librarian; Parada Literária Project.

\section{Escola: lugar de aprender a ler e de formar futuros leitores}

Um dos grandes desafios do processo educacional está pautado no aprendizado da leitura e da escrita, processo denominado de alfabetização ${ }^{3}$, sendo este processo considerado, pela maioria dos professores alfabetizadores, o ponto de partida para que os indivíduos possam se apropriar do amplo e complexo sistema linguístico, e, mas especificamente a partir do processo de alfabetização, objetiva-se formar leitores.

O que acontece no cotidiano, no entanto, é bem diferente do que se almeja. A grande maioria dos indivíduos alfabetizados, apesar de dominarem as habilidades de leitura e escrita, muito raramente se tornam leitores de fato, o que impossibilita os mesmos de compreenderem criticamente o contexto e a realidade social na qual estão imersos, situação que acomete principalmente os indivíduos menos favorecidos economicamente.

Na perspectiva crítica, defendida por Freire (1987), é preciso garantir a emancipação aos indivíduos menos favorecidos economicamente, na esfera social, através de práticas educativas que possibilitem a apreensão de conhecimentos que aproxime estes indivíduos das variedades de usos do sistema de escrita, pois esse processo influencia diretamente nas relações de poder existentes em uma determinada sociedade.

Para Kleiman (1995) o sentido de alfabetização, concebido por Paulo Freire, está relacionado ao processo que leva o indivíduo a organizar reflexivamente seu pensamento, bem como o desenvolvimento de uma consciência crítica da sociedade e das relações que nela se estabelecem, diferente do sentido de alfabetização que a restringe, apenas, às competências individuais no uso e na prática de leitura e escrita.

A partir das considerações de Freire ${ }^{4}$ (1987) e Kleiman (1995), nos aproximamos do conceito de letramento, um novo conceito, mas de grande relevância na atualidade. $\mathrm{O}$

\footnotetext{
${ }^{3}$ Utilizamos o termo alfabetização aqui como processo de decodificação e codificação do código escrito, ou simplesmente a compreensão da relação grafema fonema.

${ }^{4}$ Em toda a obra de Paulo Freire, embora não tenha utilizado o termo letramento, observa-se que o conceito do mesmo aparece implícito em sua teoria e práticas educativas, uma vez que o processo de alfabetização, para esse teórico, não deveria se resumir apenas à aquisição mecânica da leitura e da escrita, mas a mesma deveria ser considerada instrumento de compreensão das relações de poder que cercam o mundo. Paulo Freire buscava, através
} 
letramento ${ }^{5}$ busca enfatizar a importância de não apenas aprender a codificar e decodificar o código linguístico, ou seja, alfabetização, e que converge com um modelo simplificador e fragmentado de conhecimento; para a concepção de letramento é fundamental ir além, ou seja, utilizar a capacidade de codificar e decodificar nas diferentes situações em que a língua escrita nos é apresentada no meio social, e não apenas em atividades desenvolvidas no ambiente escolar.

Para Kleiman (2005, p. 11) "O letramento não é alfabetização, mas a inclui! Em outras palavras, letramento e alfabetização estão associados”. Entende-se a partir da definição de Kleiman, que os dois conceitos se complementam e são necessários para a formação de indivíduos leitores e escritores, com conhecimentos que permitam aos mesmos utilizarem as competências de leitura e escrita na diversidade de situações práticas que lhes são postas diariamente na vida cotidiana.

Ressaltamos que essa breve explanação sobre o processo inicial de aprendizado da leitura e da escrita, deve-se ao fato de considerarmos esta etapa, do processo escolar, o ponto inicial e fundamental para a formação exitosa, ou não, do futuro leitor. Acreditamos que a apresentação de bons textos, assim como a proposição de boas situações de atividades de leitura e escrita, nesta fase do processo de ensino, pode determinar o futuro da relação entre o leitor e os textos, e consequentemente com a leitura.

No caso das crianças advindas da classe baixa, a escola pública é, para a grande maioria, o único local de acesso à cultura letrada, dessa forma grande parte do futuro dos alunos, como leitores, vai ser determinada pelas experiências adquiridas pelas práticas de leitura vivenciadas no processo de escolarização, e aqui damos ênfase ao processo de alfabetização.

Sobre a relevância do processo de alfabetização como garantia do direito de ler e acesso à cultura letrada, pela classe menos favorecida economicamente, Castrilón (2011) nos afirma:

Uma vez localizadas as prioridades, e para tanto a sociedade civil pode fazer uma contribuição importante, deveria iniciar-se também com a participação pública, um amplo debate sobre a natureza das ações que poderiam conduzir a uma transformação da escola e da biblioteca. Transformação essa que habilitasse a escola para

de sua metodologia de alfabetização, formar indivíduos críticos e reflexivos, que não apenas codificassem e decodificassem a língua, mas que a utilizassem de modo compreensivo para assumir um papel na sociedade.

${ }^{5}$ Atualmente existem duas posições teóricas em relação à definição de letramento. Aqui concordamos com o posicionamento de Angela Kleiman, Magda Soares e Leda Tfouni, segundo o qual existe uma diferença entre os processos de alfabetização e Letramento, atribuindo assim definições distintas para os mesmos. Outro posicionamento é defendido por Emília Ferreiro, que acredita que no conceito de Letramento está compreendido o processo de alfabetização. 
alfabetizar, no sentido pleno da palavra, e não somente os setores privilegiados da sociedade, que de toda maneira herdam, como se herda um patrimônio familiar - segundo as palavras de Delia Lerner (2001) - sua inserção na cultura letrada. (CASTRILLÓN, 2011, p. 23 [grifos nossos]).

Dessa forma consideramos essencial que boas práticas de leitura sejam desenvolvidas

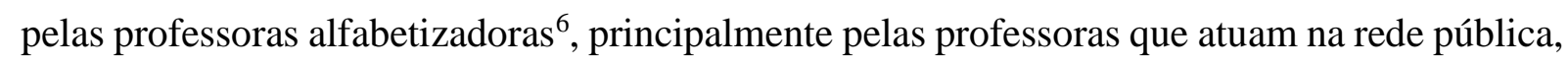
como já enfatizamos anteriormente. Professores que proporcionam boas práticas de leitura podem oportunizar aos alunos boas experiências de leitura.

Castrillón (2011) aponta questões relevantes em relação aos professores, ressaltando que é preciso que os mesmos tenham garantidos, também, o direito a uma boa formação, pois assim poderão ter melhor consciência da necessidade de uma mudança na estrutura social da escola, assim como é preciso garantir a estes professores boas condições de trabalho, ou seja, garantir uma escola bem equipada com bons materiais de leitura a serem oferecidos aos alunos.

A partir de políticas públicas que priorizem os aspectos anteriormente mencionados, formação e estruturação das escolas, poderemos vislumbrar possibilidades de mudanças em relação ao direito de ler e escrever e, consequentemente, garantir oportunidades para que a escola se constitua como meio de acesso democrático à leitura e à escrita, e o professor se constitua como mediador entre os alunos e a cultura letrada.

Sobre a função do professor como mediador de leitura em sala de aula, Zilberman (2010) propõe:

\begin{abstract}
A primeira medida a ser tomada pelo professor é, portanto, colocar os livros ao alcance dos alunos em sala de aula. A proximidade entre o leitor e o texto, na forma de livro, motiva o interesse e induz a leitura, mesmo no caso de pessoas que ainda não foram alfabetizadas. [...] Se esse princípio é válido para todos os leitores, é ainda mais decisivo no caso das crianças, cuja curiosidade é grande, estando sua atenção voltada para o visual. (ZILBERMAN, 2010, p. 149)
\end{abstract}

Na perspectiva mediadora, proposta na citação acima, a apresentação, pelo professor, de material de leitura diversificado pode estimular a aprendizagem, e, especificamente, no caso dos anos iniciais do processo escolar, esse aspecto é fundamental para despertar o interesse pelos textos, bem como proporcionar experiências significativas e decisivas para a formação de futuros leitores.

\title{
20 bibliotecário como intelectual e mediador no processo de formação de leitores
}

\footnotetext{
${ }^{6}$ Optamos por utilizar o termo professoras alfabetizadoras (gênero feminino), uma vez que esta modalidade de ensino é composta quase que em sua totalidade por mulheres.
} 
Como mencionamos no início deste trabalho, para a maioria dos indivíduos, embora nem sempre de forma exitosa, a escola é o único ponto de contato com os textos e com a cultura letrada, sendo que para aqueles que não têm oportunidade de ter acesso ou mesmo de permanecer na escola, o contato com o universo letrado torna-se quase impossível. O distanciamento progressivo do ambiente escolar, e letrado, pode assim comprometer, mais ainda, as possibilidades de formação de leitores.

A formação do leitor inicia-se na escola e perdura por toda a vida, pois esse é um processo contínuo de aprendizado. Dessa forma, o processo de formação de um leitor é sempre inconcluso, sendo uma tarefa de construção e desconstrução constante, que se modifica ao longo da sua história em um processo dialético entre vanguardas e permanências. (LAJOLO; ZILBERMAN, 1996).

A partir da explanação de Lajollo e Zilberman (1996), percebemos o quão complexo é o trabalho de formação de leitores, e mais ainda o quão grande é o desafio de formar leitores, especialmente em países periféricos e subdesenvolvidos como o Brasil, onde as políticas públicas de educação, que já não eram boas, estão caminhando para um abismo abissal.

Nesse cenário, não muito propício, a formação de leitores a partir de obras literárias pode ser caracterizada como um movimento de resistência e de transformação, por parte de professores, e demais profissionais da educação, que aceitam este desafio. Promover ações de almejem formarem leitores na escola, e fora dela, pode ser uma alternativa de resistência, e é nesse movimento de resistência que as bibliotecas e o bibliotecário passam a assumir uma função relevante no processo de formar leitores.

Na perspectiva de universalizar a cultura letrada, Castrillón (2011) nos explana sobre a responsabilidade social das bibliotecas como instrumento de democratização da leitura, e consequentemente uma democratização de conhecimento, possibilitando o exercício pleno da cidadania. Nessa perspectiva, a biblioteca e o bibliotecário assim como a escola e o professor, possuem funções análogas como agentes de mediação da cultura letrada.

Durante muito tempo, ainda no período histórico da antiguidade, as bibliotecas não apresentavam a função de divulgar e levar conhecimentos a todos. Segundo Martins apud Santos (2002), nesse período, as bibliotecas não tinham a função de difundir os livros e os conhecimentos que neles continham, ao contrário, atuavam no sentido de impedir a disseminação e divulgação dos acervos que abrigava em suas estantes. 
Nesse período, antiguidade, o significado etimológico da palavra biblioteca, oriunda do grego bibliotheke, trazia impregnado em si todo o sentido e função de criação das mesmas onde Biblio significa livro e teca significa depósito. Esta era a definição e função das bibliotecas na antiguidade: depósitos de livros.

$\mathrm{Na}$ idade média surgem as bibliotecas monacais e universitárias, entretanto, as mesmas ainda mantinham seus acervos limitados à poucos e seletos indivíduos, uma vez que nesse período a habilidade de leitura ainda era muito restrita. Com o surgimento das bibliotecas universitárias, na idade média, surge o bibliotecário como sendo o profissional responsável por organizar as informações existentes nas bibliotecas, entretanto, a função do bibliotecário, de disseminador do conhecimento, somente se consolidou no Renascimento. (SANTOS, 2012)

Embora a história das bibliotecas remonte à antiguidade, somente no Renascimento é que surge a figura do bibliotecário como mediador entre a sociedade e o conhecimento; também é no Renascimento que se inicia o processo de acessibilidade dos acervos e também o lento, e ainda inconcluso processo de democratização do o ato de ler.

Democratizar o acesso à leitura, por meio das bibliotecas ${ }^{7}$, pode ser considerado um grande desafio na atualidade. Nessa perspectiva enfatizamos a função social que passa a ser atribuída ao bibliotecário, profissional que deve buscar meios que oportunizem o acesso à informação e à aprendizagem, transformando assim a biblioteca em espaço de socialização do conhecimento.

Sob este prisma, a biblioteca deve buscar assumir o sua função social indo de encontro aos anseios da comunidade, permitindo o acesso e possibilitando a criação de espaços de convivência na biblioteca. Sobre a função social que deve ser desempenhada pela biblioteca pública, Castrillón (2011) nos afirma:

Um país requer bibliotecas que possam ir mais além desse plano mínimo de trabalho.
Bibliotecas que, em primeiro lugar, se convertam em meios contra a exclusão social,
isto é, que se constituam em espaços para o encontro, para o debate sobre os temas
que dizem respeito a maiorias e minorias; bibliotecas onde crianças, jovens e adultos
de todas as condições, leitores e não leitores, escolares e não escolares, encontrem
respostas a seus problemas e interesses e lhes sejam abertas novas perspectivas.
(CASTRILLÓN, 2011, p. 36)

Da mesma forma que consideramos relevante criar um espaço de discussão e reflexão sobre questões sociais nas bibliotecas, também, reconhecemos a relevância, através da figura

\footnotetext{
${ }^{7}$ Referimo-nos aqui às bibliotecas públicas e também às bibliotecas de instituições públicas escolares de educação básica e superior.
} 
do bibliotecário, da promoção de meios de levar a informação e o conhecimento para fora do espaço físico da biblioteca, como forma de combater a exclusão social, e dessa forma alcançar àqueles que ainda não utilizam a biblioteca como aliada na construção do conhecimento, na melhoria da qualidade de vida e, principalmente, instrumento de transformação social.

Sobre o poder da informação para melhoria da qualidade de vida das pessoas, Castrillón (2011) cita o bibliotecário brasileiro Emir Suaiden, em uma fala pronunciada em uma conferência em Madri “É cada vez mais claro que em mundo globalizado somente as pessoas com acesso à informação e ao conhecimento terão reais oportunidades para melhorar sua qualidade de vida" (p. 37).

A partir do exposto, podemos inferir sobre a relevante função do bibliotecário, que assim como o professor tem a responsabilidade de mediador do conhecimento. A visão de um profissional técnico, que organiza e cataloga livros em um espaço fechado, deve ser superada no sentido de este profissional ter um compromisso ético e político na democratização do conhecimento.

Sobre as responsabilidades do bibliotecário, como agente de democratização do conhecimento Castrillón (2011), enumera três responsabilidades:

\footnotetext{
Em primeiro lugar, organizar debates públicos que não se pareçam com um espetáculo, nem cujos temas sejam decididos exclusivamente por sua atualidade, mas sim por sua necessidade. Temas que tenham a ver com os problemas do dia a dia, mas também com outros menos conjunturais. Em segundo lugar, não se contentar com o público dos já iniciados que chega espontaneamente à biblioteca ou com o dos obrigados pela tarefa escolar, mas sim desenhar ações para que a biblioteca chegue àqueles que se sentem excluídos das atividades relacionadas com o pensamento ou com opções de avida inscritas na sociedade majoritária. Uma terceira responsabilidade que eu qualificaria de ética, refere-se à seleção de livros e à aquisição de outros materiais, escolha que também dá conta da orientação e do perfil da biblioteca e pode constituir uma forma de censura. Cuidar com especial esmero dessa seleção. (CASTRILLÓN, 2011, p. 45-46 [grifos nossos]).
}

A partir das responsabilidades, enumeradas acima, percebemos o quão importante e necessária é a função do bibliotecário, não somente para o espaço da biblioteca ou da escola, mas para o desenvolvimento intelectual de toda uma sociedade. A seguir apresentaremos uma análise, a partir de um projeto desenvolvido por uma bibliotecária de uma universidade pública de Imperatriz/MA, que converge para a segunda responsabilidade elencada por Castrillón, a de levar à informação para fora da biblioteca.

\section{A função social da biblioteca na formação de leitores - uma experiência literária em Imperatriz/MA}


Neste item do trabalho faremos uma breve análise, a partir de uma ação desenvolvida através de um projeto idealizado por uma bibliotecária de uma universidade pública de Imperatriz/MA, com o objetivo de apreender como esta bibliotecária percebe a função e a importância da biblioteca e do bibliotecário na formação de leitores em uma sociedade.

A geração dos dados fundamentou-se em uma abordagem qualitativa de pesquisa. Ao realizar a escolha pela abordagem qualitativa, optamos pela entrevista como um instrumento de geração de dados, pois este instrumento nos possibilitou conhecer aspectos relacionados à compreensão e percepção, da participante da pesquisa, em relação à temática em questão, ou seja, nos permitiu apreender a sua subjetividade em um contexto real.

A pesquisa qualitativa constitui-se uma abordagem que privilegia o fenômeno em seu contexto, em seu acontecer natural. (ANDRÉ, 1995). Segundo Flick (2004, p. 16), “A pesquisa qualitativa é orientada para a análise de casos concretos em sua particularidade temporal e local, partindo de expressões e atividades em seus contextos locais".

A partir da entrevista estruturada com a bibliotecária, idealizadora do projeto Parada Literária $^{8}$, buscamos compreender suas percepções sobre a função da biblioteca pública e do bibliotecário, bem como conhecer sua experiência com o desenvolvimento do referido projeto.

\subsection{Função da biblioteca pública e do bibliotecário}

Entrevistadora: Em sua opinião como a comunidade ver a função do bibliotecário?

Bibliotecária: Acredito que, no geral, a comunidade nos ver como a pessoa que ler muito e organiza livros na biblioteca.

Entrevistadora: Para você, como a biblioteca pública, ou de instituição pública, pode contribuir para a formação de leitores?

Bibliotecária: A biblioteca pode tornar mais fácil o acesso à livros, e informações que falem da importância do ato de ler para a formação de cidadãos pensantes. O bibliotecário deve ter essa responsabilidade [...] de facilitar o acesso, independente do suporte.

Em sua resposta a bibliotecária enfatiza a questão relacionada ao acesso das informações contidas na biblioteca, demonstrando que a mesma tem consciência de que esta

\footnotetext{
${ }^{8} \mathrm{O}$ projeto Parada Literária foi implementado no terminal de integração de ônibus de Imperatriz/MA, por iniciativa de uma das bibliotecárias da Universidade Federal do Maranhão - UFMA, em parceria com o Instituto Federal do Maranhão - IFMA e Serviço Nacional de Aprendizagem Comercial - SENAC, com o apoio da empresa Rio Anil Transportes - RATRANS. O projeto disponibilizou um armário de aço onde foi disponibilizado um acervo literário, inicialmente de 233 títulos, constituído por doações, para as pessoas que utilizam o terminal de integração de ônibus. Foi afixado no terminal um cartaz informativo sobre os procedimentos para empréstimo dos livros e também com maiores esclarecimentos sobre o projeto. Cada usuário poderia retirar um livro de sua preferência e devolvê-lo posteriormente a leitura, em um sistema definido, no projeto em questão, como auto empréstimo. $\mathrm{O}$ projeto teve duração de um ano e meio, funcionou de 07/02/2017 a 23/08/2018.
} 
responsabilidade é do bibliotecário. Ter essa consciência é um passo relevante, pois o bibliotecário se constitui como mediador entre a comunidade e o acervo que a biblioteca abriga. Aqui percebemos, na resposta dada na primeira questão, que a bibliotecária percebe que a comunidade, em geral, não tem a mesma compreensão, pois a maioria a ver apenas como alguém que ler muito e organiza os livros no espaço da biblioteca.

A visão do bibliotecário para a comunidade, na percepção da entrevistada, de ser um dedicado leitor que organiza os livros, traz arraigada uma concepção que se cristalizou a partir do período antigo, quando as bibliotecas se constituíam em locais fechados, restritos à poucas pessoas, e que pouco oportunizavam a comunidade o acesso ao acervo que continham (MARTINS apud SANTOS, 2002).

Esta percepção, bastante comum, de bibliotecário como um organizador de livros, pode contribuir para manter as bibliotecas como espaços ainda subutilizados pela comunidade em geral, inviabilizando assim o acesso dessa comunidade a esse rico espaço de socialização de conhecimento. É preciso que essa visão seja superada, pois esse pode um primeiro passo no sentido de as bibliotecas estreitarem mais os laços com a comunidade.

\subsection{O projeto Parada Literária}

Entrevistadora: Como surgiu a ideia do projeto parada literária?

Bibliotecária: Tendo em vista o grande número de doações recebidas na biblioteca, e que nem tudo pode ser inserido no acervo, pois é necessário estar no PPP - Projeto Politico Pedagógico, pensou-se em disponibilizar os livros para a comunidade de Imperatriz, para que os livros pudessem ser utilizados. Entrevistadora: Quais os pontos positivos e negativos que você identificou durante o desenvolvimento do projeto?

Bibliotecária: Um ponto positivo é que nós passamos a receber doações não mais somente para a biblioteca, mas especificamente para o projeto. Recebemos doações da Academia Imperatrizense de Letras, clubes de livro e de professores que compraram a ideia. O ponto negativo foi que o projeto demandou mais mão-de-obra e nem toda a equipe estava a favor da ideia.

Entrevistadora: Qual o motivo da descontinuidade do projeto?

Bibliotecária: Tivemos dificuldade no transporte de livros da biblioteca para o terminal de ônibus, visto que nem sempre o carro da UFMA estava disponível. Também a desvalorização, por alguns usuários do terminal como falta de cuidado e não devolução dos livros levados de empréstimo.

Entrevistadora: Como você avalia o desenvolvimento do projeto?

Bibliotecária: $O$ projeto possibilitou levar a biblioteca para fora do espaço convencional, oportunizando acesso mais fácil à leitura, buscando promover a leitura e privilegiar o leitor, como parcela de contribuição para formação dos cidadãos de uma sociedade mais livre. Contribuiu para educação inclusiva, disponibilizando informação sem barreira de custo. Acredito que promoveu oportunidades para melhorar a vida das pessoas através do acesso à informação. O projeto buscou promover o contato das pessoas que utilizam o transporte coletivo, com informações contidas nos livros para que adquirissem conhecimentos para apoiar a educação e habilidades profissionais. 
Pela fala da bibliotecária, percebemos que o fato que motivou a iniciativa do projeto pautou-se a princípio no excedente de doações recebidas pela a biblioteca, sendo que há regras para que essas doações sejam inseridas no acervo, e uma boa parte não se enquadrava nas regras propostas. Aqui nos deparamos, novamente, com a função de biblioteca trazida da antiguidade, de organizar o acervo em função do espaço. Essa função, embora outras tenham sido agregadas à figura do bibliotecário, ainda está muito presente no cotidiano da maioria das bibliotecas.

Pensar em dar uma utilidade social para o excedente de doações, no caso criando meios de levar os livros para a comunidade, nos revela uma preocupação por parte da entrevistada em oportunizar, que pessoas que não utilizam o espaço da biblioteca, tenham a possibilidade de ter acesso à informação e ao conhecimento contido nos livros.

A preocupação da entrevistada em dar uma utilidade aos livros, levando os mesmos para a comunidade, nos remete a primeira lei da biblioteconomia de Ranganathan ${ }^{9}$, Livros são para serem usados, essa é a utilidade dos livros: serem lidos. Nessa perspectiva a função do bibliotecário é desenvolver ações para tornar os livros acessíveis aos leitores, ou seja, fazer com que os livros sejam lidos. (FIGUEIREDO, 1992).

Possibilitar ações que oportunizem o acesso da comunidade ao acervo de uma biblioteca, pode ser uma forma de contribuir para a democratização do conhecimento, principalmente para aqueles que não possuem condições financeiras para adquirir os livros.

Sob esse prisma é necessário fazer com que as ações da biblioteca cheguem àqueles que não obrigados a frequentá-la por exigência de atividades escolares, e que geralmente, se sentem excluídos da cultura letrada (CASTRILLÓN, 2011).

Na sequência das respostas, ao relatar pontos positivos no desenvolvimento do projeto, percebemos, pela fala da entrevistada, que houve uma boa aceitação e apoio da comunidade para tal iniciativa, ou seja, desde que iniciativas sejam tomadas, outras instituições, geralmente, se prontificam a colaborar. $\mathrm{O}$ apoio da sociedade em geral, é extremante relevante para o desenvolvimento de práticas de inclusão e democratizadoras da cultura letrada.

Por outro lado, como ponto negativo, a própria instituição a qual a entrevistada está vinculada, parece não ter abraçado com o mesmo entusiasmo a ideia do projeto; uma vez que questões de logística, e pouco apoio de demais colegas, inviabilizaram o transporte dos livros ao terminal de ônibus, onde se encontrava o armário que continha o acervo, sendo este,

\footnotetext{
${ }^{9}$ As cinco leis da biblioteconomia do pensador indiano Ranganathan : I. Livros são para serem usados. II. Todo livro tem seu leitor. III. Todo leitor tem o seu livro. IV. Poupe o tempo do leitor. V. Uma biblioteca é um organismo em crescimento.
} 
apontado pela entrevistada, como um dos motivos que levaram à descontinuidade do projeto. Aqui, fazemos uma ressalva aos cortes de recursos financeiros aos quais as universidades têm sido alvo nos últimos três anos, podendo não ser o único, mas um dos fatores que pode ter contribuído para inviabilizar iniciativas como esta aqui descrita.

Em relação aos demais colegas, que segundo a entrevistada, não abraçaram a ideia, é possível perceber que ainda é necessário uma mudança de atitude no modo pensar, por parte de alguns profissionais da educação, que infelizmente nas palavras de Castrillón (2011) trabalham com um plano mínimo ${ }^{10}$, que pouco contribui para formação de leitores.

Outro ponto negativo referiu-se ao cuidado pelos usuários com o acervo, no caso em relação às devoluções. A entrevistada relata que na maioria dos casos, as devoluções não aconteciam. Percebe-se que a consciência dos usuários em relação ao sistema de auto empréstimo $^{11}$, não foi compreendida como uma responsabilidade que cada um tinha em relação aos livros disponibilizados para todos. Entretanto, podemos ressaltar como positivo o fato de que os livros foram utilizados, embora por um único usuário.

Apesar das dificuldades apontadas, a entrevistada avalia como positiva a inciativa, uma vez que foi possível levar um pouco da biblioteca para um espaço de acesso ao público, no caso o terminal de integração de ônibus, oportunizando e promovendo a criação de um espaço de leitura. Nessa perspectiva, a entrevistada ressalta que a leitura pode contribuir para a formação de cidadãos de uma sociedade mais livre, a partir dessa fala podemos inferir que a mesma apresenta uma visão de leitura como processo transformador na vida das pessoas e da sociedade, convergindo com a visão Freiriana da função da leitura e da escrita para os indivíduos.

Em uma perspectiva de transformação e emancipação, Paulo Freire (1987) considera a leitura, assim como a escrita, como elementos de transformação, que podem modificar a realidade social, que possibilita ao indivíduo pensar criticamente e reflexivamente sobre o mundo à sua volta, e principalmente, como instrumento de combate a exclusão social.

\section{Considerações finais}

\footnotetext{
${ }^{10} \mathrm{O}$ plano mínimo citado por Castrillón refere-se à organização dos acervos e a receber somente o público que procura o espaço da biblioteca.

${ }^{11}$ No auto empréstimo os usuários pegavam e levavam o livro que escolhessem sem precisar realizar nenhum registro tipo registro. No cartaz do projeto dizia: pegue, leve, devolva quando puder
} 
Sendo espaços de conhecimento e de socialização, as bibliotecas não podem manterse isoladas da comunidade, como ambientes restritos ao pequeno público que a frequenta, ao contrário, a biblioteca deve priorizar ações que busquem atingir ao público, principalmente o público que ainda não a utiliza como espaço de socialização de conhecimento.

O desenvolvimento de iniciativas, como o projeto parada literária, nos revela que há uma preocupação por parte de bibliotecários em possibilitar à todos o acesso à leitura. Em suas respostas, a entrevistada revelou ter consciência da função social que o bibliotecário deve exercer através de ações que possibilitem o acesso ao acervo das bibliotecas, e que o bibliotecário deve assumir a função de mediador neste processo. Na perspectiva de democratização do conhecimento e no combate à exclusão social, reconhecemos que é necessário e urgente que o potencial da biblioteca e o bibliotecário sejam utilizados ao máximo possível, tornando os acervos acessíveis a todos.

Apesar das dificuldades relatadas, ações de democratização de acesso à leitura devem ser desenvolvidas e receber apoio de toda a comunidade acadêmica. É preciso criar condições para que toda a comunidade perceba a importância da biblioteca e do bibliotecário no fomento às transformações individuais e sociais.

\section{Referências}

ANDRÉ, Marli Eliza Damazio Alonso. Etnografia na prática escolar. Campinas, SP: Papirus, 1995. Série Prática Pedagógica.

CASTRILlÓN, Silvia. O direito de ler e escrever. Tradução: Marcos Bagno. São Paulo: Editora Pulo do Gato, 2011.

FERREIRO, E; TEBEROSKY, A. Psicogênese da língua escrita. Porto Alegre: Artes Médicas, 1986.

FIGUEIREDO, Nilce Menezes. A modernidade das cinco leis de Ranganathan. Ci. Inf., Brasília, 21 (3): 186-191, set/dez. 1992

FLICK, Uwe. Uma introdução à pesquisa qualitativa. Tradução: Sandra Netz. 2. ed. Porto Alegre: Bookman, 2004.

FREIRE, Paulo. Pedagogia do oprimido. 17. ed. Rio de Janeiro, Paz e Terra, 1987.

LAJOLO, Marina, ZILBERMAN, Regina. A formação da leitura no Brasil. Série Temas. Volume 58. Literatura brasileira. São Paulo: Editora Ática, 1996.

KLEIMAN, Angela. Preciso "ensinar" o letramento? Não basta ensinar a ler e a escrever. Brasília, MEC, 2005. 
KLEIMAN, Angela. Modelos de letramento e as práticas de alfabetização na escola. In: KLEIMAN, Angela (org.). Os significados do letramento: uma nova perspectiva sobre a prática social da escrita. Campinas, SP: Mercado das letras, 1995.

SANTOS, Josiel Machado. O processo evolutivo das bibliotecas da Antiguidade ao Renascimento. Revista Brasileira de Biblioteconomia e Documentação. São Paulo, v.8, n.2, p. 175-189, jul./dez. 2012.

ZILBERMAN, Regina. A leitura e o ensino da literatura. Curitiba: Ibpex, 2010.

Enviado em 19 de setembro de 2019. Aceito em 14 de novembro de 2019. 